\title{
An Analysis of Multiple Interepisode Durations Using a Unifying Multivariate Hazard Model
}

\section{Chandra R. Bhat, Sivaramakrishnan Srinivasan, and Kay Axhausen}

Chandra R Bhat and Sivaramakrishnan Srinivasan

The University of Texas at Austin, Department of Civil Engineering,

1 University Station C1761, Austin, Texas 78712-0278

Tel: 512-471-4535, Fax: 512-475-8744,

Email: bhat@mail.utexas.edu, s.siva@mail.utexas.edu

Kay W. Axhausen

Verkehrsplanung (IVT), HIL F 32.3

ETH Hönggerberg, CH - 8093 Zürich

Tel: +41-1-633 3943, Fax: +41-1-633 1057,

Email: axhausen@ivt.baug.ethz.ch 


\begin{abstract}
This paper jointly examines the length between successive participations in several activity purposes using a 1999 multi-week travel survey conducted in the German cities of Halle and Karlsruhe. A multivariate hazard model that accommodates a flexible duration dynamics structure, recognizes the effects of covariates, incorporates the variation in interepisode duration due to unobserved individual-specific factors and variation in interepisode duration within spells of the same individual, and considers the joint nature of participation in the various activities is proposed and applied. The variables considered in the analysis include demographics, access to the internet, location characteristics, and day of week variables. The results indicate a very distinct weekly rhythm in individuals' participation in social, recreation, and personal business activities. While there is a similar rhythm even for participation in shopping activities, it is not as pronounced as for the non-shopping activity purposes. Also, individuals and spouse attributes, household characteristics, residential location and trip-making variables, and day of week effects have a strong influence on interepisode durations.
\end{abstract}




\section{INTRODUCTION}

The activity-based approach to travel demand modeling emphasizes activity participation and focuses on sequences or patterns of activity behavior (using the whole day or longer periods of time as the unit of analysis). Consequently, it offers a sound behavioral basis to assess the potential travel responses of individuals to policy actions through an examination of how people modify their activity participations (see Bhat and Koppelman, 1999, Pendyala and Goulias, 2002, and Arentze and Timmermans, 2004).

The activity-based analysis approach has seen substantial development in the past few years. However, almost all earlier studies have focused on a single day as the time period for analysis of activity-travel patterns. Such single day analyses implicitly assume uniformity and/or behavioral independence in activity decisions from one day to the next. Activity-travel models based on multiday data (data for a week or longer periods of time), on the other hand, help identify rhythms or patterns in activity-travel behavior over longer periods of time, thereby recognizing day-to-day variations and dependence in activity decisions across days. For instance, while there may be some amount of uniformity in decisions associated with workrelated patterns, many activities (such as grocery shopping or recreational pursuits) are likely to have a longer cycle for participation. In fact, even within the context of work activity and travel, there may be rather substantial variation in patterns from day-to-day in such dimensions as the number of non-work stops during the commute, location of commute-related non-work stops, departure time to work, and commute route choice (see, for example, Mahmassani et al., 1997 and Bhat and Zhao, 2002). Similarly, multiday studies recognize, for example, that an individual's likelihood of participation in shopping on any given day will tend to increase the 
longer s/he has not participated in such an activity (due to food inventory depletion effects; see Kim and Park, 1997).

Explicitly accommodating day-to-day variation in behavior and the dynamics in behavior across days can lead to better and unbiased estimations of the effect of demographic and other individual/household attributes on activity-travel choices (see Hirsh et al., 1986; Bhat et al., 2004). This, in turn, has implications for accurate travel demand forecasting in response to changing demographic profiles in the population. In addition, multi-day analyses are also required for the realistic evaluation of policy actions on activity travel patterns. Specifically, there are two main advantages of the multi-day analyses over the single-day analyses in this regard. First, multi-week analyses are able to reflect changes in the activity-travel patterns of individuals over a period longer than a day in response to policy actions such as workweek compression (Hirsh et al., 1986). Second, multi-day models explicitly accommodate the distribution of activity-travel participation over multiple days, which can have an important impact on how an individual responds to a policy measure on a shorter-term day-to-day basis. For example, an individual who has to drop off a child on one day of the week while traveling to work may "stick" with the auto mode for all days of the workweek. This individual would be reluctant to switch to other travel modes, in response to a policy action such as congestion pricing, even on days s/he is not dropping the child (see Jones and Clark, 1988 for an extensive discussion of the need for multiday analysis to examine the response to policy actions).

\subsection{Earlier Multiday Research and Substantive Focus of Current Research}

The need for multiday data and analyses has been recognized for a long time and is certainly not a new issue. Some of the early studies to explicitly analyze multiday activity-travel data for 
travel demand modeling are the works of Hanson and Huff (Hanson and Huff, 1986; 1988a; 1988b and Huff and Hanson, 1986; 1990), Pas and Koppelman (Pas, 1988; Pas and Koppelman, 1987), and Hirsh et al. (1986). Hanson and Huff used the 1971 multiweek travel survey conducted in Uppsala, Sweden in their analysis, while Pas and Koppelman used the 1973 sevenday activity diary survey conducted in Reading, England. These researchers found quite substantial day-to-day variability in activity-travel patterns from one day to the next, and questioned the ability of travel demand models based on a single day of data to produce good forecasts and accurately assess policy actions. The studies by Hanson and Huff indicated that even a period of a week may not be adequate to capture much of the distinct activity-travel behavioral patterns manifested over longer periods of time. Hirsh et al. used a one-week activity diary collected in 1983 in Israel to examine the dependence among the shopping activity participations of individuals across different days of the week, and concluded that there is not only substantial day-to-day variation in shopping patterns but also significant dependence in activity decisions across days.

A few more recent studies along the same vein as the studies discussed above include Kunert (1994), Ma and Goulias (1997), Pas and Sundar (1995), Muthyalagari et al. (2001), Schlich (2003, 2004), and Schönfelder and Axhausen (2004). Kunert used a one-week travel diary collected in Amsterdam and Amstelveen in 1976 to examine interpersonal and intrapersonal variations in trip rates for sixteen life cycle groups. Kunert found that the average intrapersonal variance is about $60 \%$ of the total variation in trip rates and concluded that "even for well-defined person groups, interpersonal variability in mobility behavior is large but has to be seen in relation to even greater intrapersonal variability”. Ma and Goulias examined activity and travel patterns using data from the Puget Sound (Seattle) Transportation Panel, and 
suggested that activity patterns show even greater day-to-day variation than travel patterns. Pas and Sundar examined day-to-day variability in several travel indicators and across household members using a three-day travel diary data collected in 1989 in Seattle, while Muthyalagari et al. studied intrapersonal variability using GPS-based travel data collected over a period of six days in Lexington, Kentucky. The study by Muthyalagari et al. study found larger day-to-day variability estimates than those obtained by Pas and Sundar, suggesting that GPS-based data collection may be recording short and infrequent trips better than traditional surveys. Schlich (2003, 2004) used a sequence alignment method to analyze intrapersonal variability in travel behavior using the 6-week Mobidrive travel survey conducted in Germany in 1999. Finally, Schönfelder and Axhausen (2004) recently analyzed activity episode location rhythms to illustrate the frequent participation at a small set of core locations and the constant rate of innovation manifesting itself in never-before visited locations. They used several recent multiweek surveys and GPS studies conducted in Europe for their analysis.

All the studies discussed thus far examine day-to-day variations in the context of both regular daily activities (such as work-commute patterns) as well as non-daily activities (such as grocery shopping participation and related patterns). A few other studies, on the other hand, have specifically focused on day-to-day variations in regular work activities. Mahmassani et al. (1997) descriptively examined the effect of commuter characteristics and the commuter's travel environment on the likelihood of changing departure time and route choice from one day to the next for the morning home-to-work trip. Hatcher and Mahmassani (1992) focused on the same travel dimensions as Mahmassani et al. (1997), except that their emphasis was on the evening work-to-home commute rather than the morning home-to-work commute. A ten-day diary data of morning and evening commute characteristics collected in Austin in 1989 is used in both these 
studies. Bhat (2000a) examined interpersonal and intrapersonal variation in the context of work commute mode choice, while Bhat (2001) studied interpersonal and intrapersonal variation in the context of the number of non-work commute stops made by commuters. A multiday travel survey data collected in the San Francisco Bay area in 1990 is used in both these studies.

The above studies have contributed to our understanding of multiday activity-travel behavior. However, they have mainly focused on either descriptively examining the extent of interpersonal and intrapersonal variations in activity-travel behavior or on examining day-to-day variations in the context of regular daily work activity. In this research, we focus on a rigorous modeling approach to examine the rhythms of individuals over a multiweek period. In addition, an important contribution of this research is to distinguish between participation in different activity purposes using multiweek data and to accommodate the dependencies in the participation across activity purposes. Specifically, the current study examines the participation of individuals, and the dependence in participation of individuals, in five different non-work activity purposes: recreation, social, personal business, maintenance shopping (groceries, laundry, etc.), and non-maintenance shopping (buying clothes, window shopping, etc.). A continuous six-week travel survey collected in the cities of Halle and Karlsruhe in Germany in the Fall of 1999 is used in the analysis.

\subsection{Methodological Focus of Current Research}

An examination of the participation of individuals in different activity purposes across multiple days is achieved in the current paper by analyzing the duration between successive activity participations of individuals in each activity purpose. The interepisode duration is measured in days, since a vast majority of individuals had no more than a single activity participation in each 
of the activity purposes on any given day. The methodology uses a hazard-based duration model structure since such a structure recognizes the dynamics of interepisode duration; that is, it recognizes that the likelihood of participating in an activity depends on the length of elapsed time since the previous participation. The hazard duration formulation also allows different individuals to have different rhythms in behavior and is able to predict activity participation behavior (both frequency and distribution of the activity participations) over any period of time (such as a day, a week, or a month).

Hazard models are seeing increasing use in the transportation and marketing field (Bhat, 2000b and Bhat et al., 2004 provide extensive reviews of transportation-related applications, while Seetharaman and Chintagunta, 2003 review marketing-related applications). In the context of examining interepisode durations from multiweek data, there have been three recent applications of hazard models: Schönfelder and Axhausen (2000), Kim and Park (1997), and Bhat et al. (2004). However, all these studies focus on the single activity purpose of shopping. Other activity purposes, and the dependencies across activity purposes, are not considered. Further, these earlier studies do not consider intra-individual variations in intershopping duration. In the current study, we develop a formulation that (a) accommodates a very flexible structure to account for the dynamics of participation decisions across multiple days within each activity purpose, (b) includes the effect of demographic, locational, computer use, and day-ofweek attributes on interepisode durations, (c) recognizes the presence of unobserved individualspecific attributes affecting interepisode durations, (d) incorporates intra-individual variations in interepisode duration due to unobserved characteristics, and (e) recognizes the dependence among interepisode durations of each type due to unobserved individual-specific characteristics. 
To our knowledge, this is the first formulation and application of a generalized multidimensional duration modeling framework that accommodates all the issues discussed above. ${ }^{1}$

The rest of this paper is structured as follows. Section 2 presents the model structure and estimation details. Section 3 describes the data. Section 4 discusses the empirical results. Finally, Section 5 concludes the paper.

\section{THE MODEL}

\subsection{Hazard-Based Duration Structure}

Let $T_{q m i}$ be an index representing the $i^{\text {th }}$ interepisode spell of activity purpose $m$ for individual $q$.

Let $\tau$ represent some specified time on the continuous time scale. Let $\lambda_{\text {qmi }}(\tau)$ represent the hazard at continuous time $\tau$ since the previous episode participation in purpose $m$ for the $i^{\text {th }}$ interepisode duration spell of individual $q$; i.e., $\lambda_{q m i}(\tau)$ is the conditional probability that individual $q$ 's $(i+1)^{\text {th }}$ episode of activity purpose $m$ will occur at continuous time $\tau$ after her/his $i^{\text {th }}$ participation, given that the episode does not occur before time $\tau$ :

$$
\lambda_{q m i}(\tau)=\lim _{\Delta \rightarrow 0^{+}} \frac{P\left(\tau<T_{q m i}<\tau+\Delta \mid T_{q m i}>\tau\right)}{\Delta}, q=1,2, \ldots, Q ; m=1,2, \ldots, M ; i=1,2, \ldots, I_{q m}
$$

Next, we relate the hazard rate, $\lambda_{q m i}(\tau)$, to a baseline hazard rate, $\lambda_{m 0}(\tau)$, a vector of demographic, locational, and episode-specific covariates, $x_{q m i}$, an individual-specific unobserved factor $v_{q m}$ capturing miscellaneous individual attributes affecting interepisode duration (for

\footnotetext{
${ }^{1}$ There have been a couple of papers in the literature focusing on multidimensional duration modeling (see Lilliard, 1993 and Chintagunta and Haldar, 1998). However, these studies have used restrictive specifications for the baseline hazard and/or allow only restrictive correlations in the hazards. Further, the studies focus on only two hazards and it is not at all clear how the model structures can be extended beyond two hazards.
} 
example, an intrinsic preference for shopping or recreation), and a spell-specific unobserved component $\varpi_{q m i}$. We accomplish this by using a proportional hazard formulation as follows:

$\lambda_{q m i}(\tau)=\lambda_{m 0}(\tau) \exp \left(-\beta_{m}^{\prime} x_{q m i}-v_{q m}+\varpi_{q m i}\right)$

where $\beta_{m}$ is a vector of covariate coefficients. The reader will note that the variance of $\varpi_{q m i}$ captures unobserved intra-individual variation (or heterogeneity) in the interepisode hazard. The term $v_{q m}$, on the other hand, captures idiosyncratic individual specific effects. The variance of $v_{q m}$, therefore, captures unobserved inter-individual variations (or unobserved inter-individual heterogeneity) in the interepisode hazard (see Kiefer, 1988 and Bhat, 1996 for discussions regarding the importance of capturing unobserved heterogeneity in hazard models). In this paper, we assume that $v_{q m}$ is normally distributed across individuals and that $\varpi_{q m i}$ is independent of $v_{q m}(m=1,2, \ldots, M)$. For reasons that will become clear later, we assume a gamma distribution for $\exp \left(\varpi_{q m i}\right)$.

The proportional hazard formulation of Equation (2) can be written in the following equivalent form (see Bhat, 2000b):

$$
S_{q m i}^{*}=\ln \int_{\tau=0}^{T_{q m i}} \lambda_{m 0}(\tau) d \tau=\beta_{m}^{\prime} x_{q m i}+v_{q m}-\varpi_{q m i}+\varepsilon_{q m i},
$$

where $s_{q m i}^{*}$ is the (log) integrated hazard at time $T_{q m i}$ for activity purpose $m$ and spell $i$ and $\varepsilon_{q m i}$ is a random term with a standard extreme value distribution: $\operatorname{Prob}\left(\varepsilon_{q m i}<z\right)=F_{\varepsilon}(z)=1-\exp [-$ $\exp (z)]$

Now, consider the case when the continuous variable $T_{q m i}$ is unobserved. However, we do observe the discrete time intervals of interepisode duration, where the discrete interval is in the unit of a day. Let $t_{\text {qmi }}$ represent the $i^{\text {th }}$ interepisode duration of activity purpose $m$ (in days) 
for individual $q$ and let $k$ be an index for days (thus, $t_{q m i}=1,2, \ldots k, \ldots K_{m}$, where $k$ is in days).

Defining $\tau^{k}$ as the continuous time representing the upper bound of the $k^{\text {th }}$ day, we can write

$$
\begin{aligned}
& s_{q m i}^{*}=\ln \int_{\tau=0}^{T_{q m i}} \lambda_{m 0}(\tau) d \tau=\beta_{m}^{\prime} x_{q m i}+v_{q m}-\varpi_{q m i}+\varepsilon_{q m i}, \\
& t_{q m i}=k \text { if } \psi_{m, k-1}<s_{q m i}^{*}<\psi_{m, k}, \text { where } \psi_{m, k}=\ln \int_{\tau=0}^{\tau^{k}} \lambda_{m 0}(\tau) d \tau .
\end{aligned}
$$

Equation (4) applies to each individual activity purpose $m(m=1,2, \ldots, M)$. If there were no dependence between the random terms $v_{q m}$ across activity purposes, the interepisode models can be estimated separately for each activity purpose. However, it is quite possible that individuals have similar (or opposite) participation preferences for a certain subset of activity purposes. For example, an individual predisposed to a higher participation rate in recreational activities because of her/his intrinsic preferences may also be predisposed to a higher participation rate in social activities (i.e., an individual with a lower duration length between successive recreational episode participations may also have a lower duration length between successive social episode participations). To accommodate such dependencies among activity purposes, we allow the $v_{q m}$ terms to be correlated across purposes for each individual $q .{ }^{2}$ Let $v_{q}=\left(v_{q 1}, v_{q 2}, \ldots, v_{q m}\right)^{\prime}$, so that $v_{q}$ is distributed multivariate normal: $v_{q} \sim N(0, \Omega)$. Also, let $c_{q m i}=\exp \left(\varpi_{q m i}\right)$, which is gamma-distributed by assumption as indicated earlier, have a mean one (an innocuous normalization for identification purposes) and a variance $\sigma_{m}^{2}\left(\sigma_{m}^{2}\right.$ provides an estimate of unobserved intra-individual heterogeneity in the interepisode hazard).

\footnotetext{
${ }^{2}$ The reader will note that, in contrast to a competing risk formulation in which multiple durations outcomes can end because of one of multiple outcomes, the current study is a joint duration process with correlation among the duration hazards.
} 


\subsection{Model Estimation}

The parameters to be estimated in the multivariate hazard model include the $\beta_{m}$ and $\psi_{m}$ vectors $\left(\psi_{m}=\left[\psi_{m, 1}, \psi_{m, 2}, \ldots, \psi_{m, K_{m}-1}\right]^{\prime}\right)$ for each purpose $m$, the scalar $\sigma_{m}$ for each purpose, and the matrix $\Omega$. To develop the appropriate likelihood function for estimation of these parameters, we begin with the likelihood of individual $q$ 's $i^{\text {th }}$ interepisode duration in purpose $m$. This can be written from Equation (4), and conditional on $v_{q m}$ and $\varpi_{q m i}$, as:

$$
\begin{aligned}
& L_{q m i} \mid v_{q m}, \varpi_{q m i}=\left[\left(\exp \left\{-B_{\left(t_{q m i}-1\right)} \cdot c_{q m i}\right\}\right)-\left(\exp \left\{-B_{t_{q m i}} \cdot c_{q m i}\right\}\right)\right] \text {, where } \\
& B_{t_{q m i}}=\exp \left\{\psi_{t_{q m i}}-\left[\beta_{m} x_{q m i}+v_{q m}\right]\right\} \text { and } c_{q m i}=\exp \left(\varpi_{q m i}\right)
\end{aligned}
$$

Next, the likelihood function for individual $q$ 's $i^{\text {th }}$ interepisode duration spell of purpose $m$, unconditional on $\varpi_{q m i}$, may be written as:

$$
L_{q m i} \mid v_{q m}=\int_{0}^{\infty}\left[\exp \left\{-B_{t_{q m i}-1} \cdot c_{q m i}\right\}-\exp \left\{-B_{t_{q m i}} \cdot c_{q m i}\right\}\right]
$$

Using the moment-generating function properties of the gamma distribution (see Johnson and Kotz, 1970), the expression above reduces to:

$$
L_{q m i} \mid v_{q m}=G_{\left(t_{q m i}-1\right)}-G_{t_{q m i}}, \text { where } G_{t_{q m i}}=\left[1+\sigma_{m}^{2} B_{t_{q m i}}\right]^{-\sigma_{m}^{-2}}
$$

The gamma distribution for $c_{q m i}$ is convenient because it results in a closed-form expression in Equation (7). The likelihood function for all the interepisode duration spells of purpose $m$ for individual $q$, conditional on $v_{q m}$, is:

$$
L_{q m} \mid v_{q m}=\prod_{i=1}^{I_{q m}}\left(L_{q m i} \mid v_{q m}\right)
$$

Collecting all the purpose-specific error terms $v_{q m}$ into a single vector $v_{q}$ for individual $q$, we can write the likelihood of the entire string of spells of all purpose types for individual $q$ as: 


$$
L_{q} \mid v_{q}=\prod_{m=1}^{M} \prod_{i=1}^{I_{q m}}\left(L_{q m i} \mid v_{q m}\right)
$$

and the unconditional likelihood can be written as:

$$
L_{q}=\int_{v_{q}} \prod_{m=1}^{M} \prod_{i=1}^{I_{q m}}\left(L_{q m i} \mid v_{q m}\right) d F\left(v_{q}\right) \text {. }
$$

where $F$ is the multivariate cumulative normal distribution. Finally, the log-likelihood function is $L_{q}=\sum_{q} \ln L_{q}$. The dimensionality of the integration in Equation (10) is equal to the number of activity purposes $M$. In the empirical context of the current paper, we examine five purposes, resulting in a five-dimensional integral in the likelihood function for each individual. To maximize this likelihood function and estimate the parameters, we apply simulation techniques that approximate the individual likelihood function $L_{q}$ in Equation (10) by computing the integrand in the equation at different realizations of $v_{q}$ drawn from a multivariate normal distribution, and computing the average over the different values of the integrand. The convergent parameter vector is estimated as the value that maximizes the simulated function as computed above. Under rather weak regularity conditions, the maximized (log) simulated likelihood (MSL) estimator is consistent, asymptotically efficient, and asymptotically normal (see Hajivassiliou and Ruud, 1994; Lee, 1992).

In the current paper, we use a quasi-Monte Carlo (QMC) method to draw realizations for $v_{q}$ from the multivariate normal distribution. Specifically, we use 150 draws of the Halton sequence (details of the Halton sequence are available in Bhat, 2001; 2003).

Two additional issue needs discussion at this point. First, the Halton draws do not reflect the desired correlation matrix $\Omega$ of the multivariate distribution of $v_{q}$. They are rather univariate draws for each dimension. To translate the univariate Halton draws to the multivariate Halton 
draws, we apply the Cholesky decomposition of the variance-covariance matrix $\Omega$ to the univariate draws (see Train, 2003; p. 211). In addition, to ensure the positive-definitiveness of the correlation matrix $\Omega$, we parameterize the likelihood function in terms of the elements of the Cholesky decomposed-matrix of $\Omega$ rather than using the elements of $\Omega$ directly. After obtaining the convergent parameter values in terms of the Cholesky decomposed-matrix of $\Omega$, we obtain the equivalent convergent values of $\Omega$. Second, after estimating the threshold parameters (the $\psi$ values), one can obtain the non-parametric baseline hazard form using the procedure discussed in Bhat (1996).

\section{THE DATA}

\subsection{Data Source}

The data source for the current study is a 6-week travel survey conducted in Karlsruhe (West Germany) and Halle (East Germany) as part of the MobiDrive study funded by the German Ministry for Research and Education (see Axhausen et al., 2002, for a detailed description of this data source). The main objective of this travel survey data collection was to facilitate a better understanding of the rhythms, routines, and habits of individuals over an extended time period of several weeks. The data collection effort was initiated by contacting a sample of households randomly selected from a phonebook database in each of the two cities. A subsample of this larger sample of households was selected for administration of the travel survey, based on eligibility considerations and willingness to participate (only households who did not plan to take a vacation of more than a week during the survey period and who did not have children under the age of 6 years were deemed eligible). 
The final sample from the survey included information on 361 individuals from 162 households. Of these, 44 individuals from 23 households in Karlsruhe participated in a pretest survey, and 317 individuals from 139 households in Karlsruhe and Halle participated in the main survey. The structure and administration procedures were identical in the two surveys. The pretest travel survey was administered between May $31^{\text {st }}$ and July $25^{\text {th }}$, and the main survey was administered between September $13^{\text {th }}$ and November $14^{\text {th }}$. In addition to the six-week continuous travel diary, information on the sociodemographic characteristics of households and their members, car fleet size and composition, and attitudes toward different modes of transport was also collected (the reader is referred to Schlich et al. (2000) and Chalasani and Axhausen (2004) for a detailed description of the survey).

\subsection{Sample Used and Description}

Five non-work activity purposes are considered for the multivariate interepisode duration analysis in the current paper: (1) maintenance shopping (grocery shopping, medical drug shopping, etc.), (2) other shopping (buying clothes, shoes, window shopping, etc.), (3) social (meeting friends and family, group/club meetings, and participation in restaurant, culture, and spectator sports activities), (4) recreation (active sports, walk/stroll, culture and nature excursions, short vacation, garden/cottage activities, cinema, etc.), and (5) personal business.

The sample used in the current analysis includes the interepisode duration spells of 192 adult individuals (an adult individual is defined as a person whose age is equal to or over 16 years). We confined the analysis to only those adult individuals who pursued at least two episodes of each of the five activity purposes defined earlier (this provides at least one completed interepisode duration spell of each activity purpose). 
Table 1 provides aggregate statistics (range and mean) on the number and length of interepisode duration spells for each activity purpose. The second column indicates a substantial range in the number of interepisode spells contributed by individuals. The mean values (in parenthesis) show that participation in maintenance and recreational activity purposes is generally more prevalent in the sample of individuals than participation in other purposes. The participation in "other shopping” is the least among all activity purposes, on average. The third column indicates substantial variation in the length of interepisode duration spells for each activity purpose. The reader will note that this variation is both because of difference in spell lengths across individuals and within individuals. The empirical analysis in this paper disentangles the inter-individual and intra-individual variations in spell length, and also attributes the variation to systematic (due to observed characteristics) and unobserved factors. The mean values (in parenthesis) of the spell lengths reflect our observations from the statistics on number of spells per person. Specifically, the mean interepisode spell length for maintenance and recreation are smaller than for other activities, and the mean interepisode spell length for "other shopping” pursuits is largest. The fourth column presents the upper end cut-off of the interepisode duration length used in the current empirical analysis. This upper end cut-off is needed in estimation because of the very few spells beyond a certain duration length. For example, there are only 23 spells out of 2262 spells, or $1 \%$ of spells, with a length of more than 16 days in the sample for maintenance shopping. Consequently, it is not possible to estimate a non-parametric hazard for each day beyond 16 days, and so spell lengths of 16 days or more are collapsed into a single "16 or more days" category. The numbers in the fourth column of Table 1 provide the cut-off used for each purpose and the percentage of spells in the sample with a length 
longer than the cut-off value (in parenthesis). For all activity purposes, the percentage of spells above the cut-off is less than or equal to $1 \%$ of the entire sample.

Table 1 provides information on the range and mean values of the length of interepisode duration spells, but does not provide details of the distribution of spell lengths. One way to descriptively examine the spell length distribution is to plot the sample hazards for each activity purpose. The sample hazard value for day $d$ is the share of interepisode durations ending at day $d$ from the set of all interepisode durations that have not terminated until day $d$ (see Kiefer, 1988).

The sample hazards are presented in Figure 1 (for maintenance and other shopping activity purposes) and in Figure 2 (for the social, recreation, and personal activity purposes). All the sample hazards are relatively high in the first few days, reflecting the high number of short intershopping durations in the sample. Beyond these first few days, the profile is non-monotonic without a clear positive (snowballing) or negative (inertial) duration dependence. This "randomness" in the hazard distributions is because the sample hazard does not consider the effect of covariates and the variations in the hazard due to unobserved intra-individual and interindividual factors. The baseline hazard that considers the effect of covariates and recognizes the presence of unobserved factors provides a better picture of duration dynamics, and will be presented later in Section 4.1. However, even the sample hazard reveals small spikes at 7 and 14 days for all activity purposes (especially for the non-shopping purposes in Figure 2), indicating a certain level of rhythmic weekly activity participation in all activities.

\subsection{Variable Specifications}

The choice of variables for potential inclusion in the model was guided by previous research and intuitive arguments regarding the effect of exogenous variables on activity participation. Four 
broad sets of variables were considered: individual and spouse characteristics, household characteristics, location and trip-making characteristics, and day of week variables.

Individual and spouse characteristics explored in our specifications included dummy variables for sex, ethnicity, education level, vehicle license holding, marital status, employment status (part-time employed, full-time employed, self-employed, and not employed), and linear and non-linear representations of work hours per week and age. Household characteristics considered in the model included household size, family structure, the number and employment status of household adults, household income, household tenure status (own or rent), household dwelling type (single family unit, duplex, apartment, etc.), number of motorized vehicles, number of dogs, and communication-related connections (such as number of telephones, number of private e-mail addresses, number of fax machines, and access to internet at home). Location and trip-making characteristics included whether the household is located in Karlsruhe or Halle, the population density of zone of residence, area type variables classifying the residential zone of households into one of four categories (urban, urban-suburban, suburban, and rural), the most frequently used mode for activity participation, the percentage of episodes of each type chained with other activities, and accessibility to transit. The day of week effect was represented by a series of dummy variables for each day (with one of the days being the base category).

We arrived at the final specification based on a systematic process of eliminating variables found to be insignificant in previous specifications and based on considerations of parsimony in representation. Table 2 provides a list of individual-level exogenous variables included in the final specification and their descriptive statistics in the sample. 


\section{EMPIRICAL RESULTS}

The results are presented in four sections. The first section discusses the baseline hazard estimates for each of the activity purposes. Section 4.2 interprets the covariate effects. Section 4.3 presents and intuitively explains the unobserved heterogeneity effects. The reader will note that the baseline hazard, the covariate effects, and the unobserved heterogeneity effects are all estimated simultaneously, but are discussed in separate sections for presentation ease. Also, all these effects are estimated jointly across the various activity purposes. The final section (Section 4.4) discusses model fit statistics.

\subsection{Baseline Hazard}

The baseline hazard functions for the two shopping activities are shown in Figure 3, and the baseline functions for the other three non-shopping activity purposes are presented in Figure 4. The baseline hazards for the two shopping activities indicate a general and distinct upward trend. That is, individuals are more likely to engage in shopping as the time elapsed since the previous participation increases. This can be attributed to a "depletion of inventory" effect for food items and other non-grocery items. The baseline hazards for the social, recreational, and personal business activities do not show a clear distinct upward trend as do the hazards for the shopping categories. On the other hand, there are clear spikes at 7 and 14 days for the non-shopping activity purposes in Figure 4, suggesting a rhythmic weekly pattern of participation in the nonshopping activities (there is also a spike at 12 days for the recreation activity purpose). While there is some evidence of similar weekly rhythms for the shopping activities in Figure 1, they are not as pronounced as for the non-shopping activities. 
The reader will note the clear differences between the baseline hazard profiles in Figures 3 and 4, and the corresponding sample hazard profiles in Figures 1 and 2. First, the baseline hazards are either flat or increasing between 1 to 5 days while the sample hazards are decreasing during the same period. Second, the baseline hazard for the shopping categories reveals a general increasing trend while the sample hazard shows a general decreasing or flat trend for these categories. Clearly, the baseline trend is more intuitive and reasonable because of inventory depletion effects. Third, the weekly rhythms (spikes at 7 and 14 days) as reflected in the baseline hazard are much more pronounced than in the sample hazard. These differences between the baseline and sample hazards emphasize the need to recognize the variations in interepisode duration due to covariates and intra-individual/ inter-individual differences.

To summarize, two general conclusions may be drawn from the above results. First, the shopping hazards show positive duration dependence and a mild weekly rhythmic pattern; the non-shopping hazards show a relatively flat profile, but with very prominent weekly rhythmic pattern. Thus, inventory depletion appears to drive shopping patterns, while weekly rhythm appears to drive the non-shopping patterns. Second, the hazard functions are anything but smooth and monotonic. Consequently, parametric hazard functions used commonly in transportation are not suitable for interepisode duration analysis. A non-parametric approach is more appropriate for accommodating non-monotonic and multi-spike profiles, and is also able to handle multiple participation episodes during the sample day (i.e., ties in interepisode duration).

\subsection{Covariate Effects}

In this section, we discuss the effect of covariates on the duration hazard for all the five activity purposes. It should be observed from Equation (2) that a positive coefficient on a covariate 
implies that the covariate lowers the hazard rate, or equivalently, increases the interepisode duration (decreases episode participation frequency over a multiday period). Alternatively, a negative coefficient on a covariate implies that the covariate increases the hazard rate, or equivalently, decreases the interepisode duration (increases episode participation frequency).

Table 3 shows the estimated covariate effects for the final model specification. These effects are discussed by variable category in the subsequent sections. However, before proceeding to a discussion of the covariate effects, an important note is in order here. Some of the independent variables used here may be endogenous to (or co-determined with) interepisode durations. This is particularly the case with the trip-making characteristics discussed in Section 4.2.3. That is, it is possible that the primary mode used for episode participation and the percentage of episodes of each activity purpose chained with other episodes are co-determined with interepisode durations. The discussion of variable effects should be viewed with caution because of the above issue.

\subsubsection{Effect of Individual and Spouse Characteristics}

The effects of employment-related variables within the class of individual and spouse characteristics indicate that individuals who work full-time (greater than 20 hours per week) have a lower hazard (i.e. higher interepisode duration or lower frequency of participation) for non-maintenance shopping activities relative to other individuals (however, there are no systematic variations in the non-maintenance shopping hazard among full-time employed individuals based on number of work hours). The results also show that individuals who work longer have a lower hazard (i.e. a higher interepisode duration) for maintenance activities than individuals who work shorter durations. These employment-related effects on shopping activity 
participation have also been found in earlier single-day and multi-day studies (for example, see Kitamura, 1988, Ma and Goulias, 1999, and Goulias and Kim, 2001), and are likely to be manifestations of tighter time constraints for individuals who are employed full-time and work long hours. ${ }^{3}$ The effects of the employment variables (full-time employed dummy variable and number of work hours) for the recreational activity purpose are interesting. The positive coefficient on number of work hours indicates that longer hours of work implies a lower hazard or longer inter-recreation duration, presumably because of time constraints. But this time constraint effect is tempered for full-time employed individuals (note that the overall coefficient on work hours is positive even for full-time employed individuals: the magnitudes of the coefficients on the full-time employed dummy variable and the number of work hours suggests that the coefficient on work hours is positive beyond 21 hours for full-time employed individuals, which is exactly the threshold point for defining a full-time employed individual). A possible reason for the tempering effect of time constraints for full-time employed individuals is that these individuals are intrinsically more dynamic "go-getters", who place a premium on physical and mental activity/relaxation. Finally, within the group of employment variables, spousal employment leads to a higher interepisode hazard for maintenance shopping, possibly due to higher responsibilities for household maintenance shopping if an individual's spouse is employed (we also explored the interaction effects of employment status and weekend participation on the interepisode hazards for all the activity purposes to examine any differential preferences between employed and unemployed individuals for weekend activity pursuits; the only interaction effect that turned out to be significant was for the recreational activity purpose, and we discuss this effect under day of week effects). Recent studies examining household

\footnotetext{
${ }^{3} \mathrm{~A}$ few recent studies have incorporated time-space prism concepts in single purpose, single day, activity behavior modeling to explicitly capture constraint effects (see Pendyala et al., 2002, Yamamoto et al., 2004). This is an area for further exploration in future studies in the context of multi-purpose, multiday, activity behavior modeling.
} 
interactions in activity-travel generation using single-day data have also reported such a positive impact of spousal employment on the frequency of maintenance trips undertaken by a person (Simma and Axhausen, 2001).

The effect of age is included as a non-linear effect (the non-linear specification turned out to be better than a linear representation). The results show that teenagers participate less frequently in maintenance shopping, recreation, and personal business activities and more frequently undertake social activities, compared to other adults. This is not unexpected, since teenagers are likely to "hang out" with their friends in a social setting and share less of the maintenance responsibilities of the household compared to their older counterparts. The only other age-related effect is the higher hazard (or lower interepisode duration /higher participation rate) of seniors (age $>65$ years) in personal business activities.

The impacts of other variables within the class of individual and spousal characteristics show the higher participation rate of women in maintenance shopping (a recurring finding in the literature; see Frusti et al., 2003), and the higher participation rates of retired individuals in maintenance and personal business activities. The results also show that women and married individuals participate in recreational activities less frequently, a finding noted earlier by Bhat and Misra, 2002).

\subsubsection{Effect of Household Characteristics}

The effect of household characteristics indicates that individuals in nuclear family households have a higher hazard for maintenance shopping compared to other households. This may be attributed to the higher household responsibilities and maintenance needs of nuclear family households. On the other hand, individuals in nuclear family households have a lower hazard for 
recreational pursuits, perhaps again due to the higher household responsibilities and biological demands of young children and infants. ${ }^{4}$ The influence of income on the hazard of "other (nonmaintenance) shopping” and recreational activities is intuitive, and reflects the higher expenditure potential of high-income households for out-of-home discretionary activities (see Goulias and Kim, 2001 and Bhat and Gossen, 2004 for similar results in a single-day context). Interestingly the results show that the number of motorized vehicles does not have any statistically significant effect on participation rates in each (and all) activity purposes. This may be because of one or both of the following reasons. First, the urban transit levels of service are very good in Karlsruhe and Halle, and this leads to less general dependence on motorized vehicles for transport. Second, individuals and households may locate themselves based on their mobility preferences and motorized vehicle ownership desires. For example, individuals and households who are unable to, or choose not to, own motorized vehicles may locate themselves in areas with very good transit services or easy cycling so that their mobility desires can be satisfied without a car. This self-selection in residential location gets manifested as a lack of impact of motorized vehicle ownership on activity participation rates. The impact of single family or duplex dwelling shows that individuals residing in such dwellings have a lower hazard for maintenance shopping and recreational activity participation. The effect on maintenance shopping is, however, only marginally significant. The impact on out-of-home recreational activities is partly a substitution effect through increased in-home and garden activities, as well as an income effect through the higher mortgage payments. The last two variables under household characteristics reflect a substitution effect of access to the internet on nonmaintenance shopping and the substantial positive impact of the presence of dogs in a household

\footnotetext{
${ }^{4}$ The biological demands of young children and infants include the need to feed, sleep, and be diaper-changed. Young children and infants are significantly dependent on parents in the household to satisfy these biological demands, leaving less time for parents in such households to undertake recreational pursuits.
} 
on the recreational activity pursuits (such as walking the dog) of individuals in the household. Of course, both these results must be interpreted with caution. Specifically, these effects may not be true causal effects. For example, the impact of number of dogs on higher recreational participation may simply again be a self-selection effect, as dog-owners may be more physical activity-inclined compared to non-dog owners.

\subsubsection{Effect of Location and Trip-Making Characteristics}

The effects of location and trip-making characteristics may be interpreted as follows: (a) Individuals residing in Karlsruhe have a higher hazard (lower interepisode duration) for participation in social and personal business activities compared to individuals in Halle, reflecting taste differences, a smaller selection of recreational opportunities in the economically depressed Halle, and differences in the allocation of household budgets between East- and WestGerman households (b) Individuals who use a car as the primary mode to participate in shopping (especially maintenance shopping) have a lower intershopping hazard (higher intershopping duration or less frequent shopping) than those who use other modes (this may reflect the ability to carry large amounts of groceries if a car is used, resulting in less need to shop frequently), (c) Individuals who chain participations with other activity stops participate in all activity purposes more frequently, except recreation (perhaps due to the relative ease of participating in activities if the activity is chained with other activities; however, none of these effects are very statistically significant), and (d) Suburban residents and residents of locations with excellent transit service have higher hazards (or lower interepisode durations/higher participation rates) in personal business activities. 


\subsubsection{Effect of Day of Week Variables}

The final set of covariates corresponds to day of week effects. These effects suggest the higher likelihood of participation in maintenance shopping on Fridays and Saturdays, the normal shopping days in Germany. The marginally significant impact for Sunday is likely to be linked to shopping for fresh bread and related groceries, as the range of goods obtainable in Germany is limited by law to such goods on Sundays. The higher participation rates in social activities on Mondays do not have a clear interpretation and is only marginally significant. The concentration of recreational activities by employed individuals over the weekend is an expected result, reflecting time availability for participation in leisure.

\subsection{Unobserved Heterogeneity Results}

The model system used in this paper accommodates (a) Variations in interepisode hazard due to unobserved individual-specific factors (inter-individual heterogeneity), (b) Covariation in the interepisode hazards of different activity purposes generated by unobserved individual-specific factors, and (c) Variations in interepisode hazard due to unobserved factors not related to individual characteristics (intra-individual heterogeneity). In the next section, we discuss the first two elements listed above. In the subsequent section, we present the results for unobserved intraindividual heterogeneity. In Section 4.3.3, the covariate effects and unobserved heterogeneity results are interpreted in the context of the fraction of variation in interepisode hazard explained by covariates and by unobserved factors. 


\subsubsection{Unobserved Inter-Individual Heterogeneity and Covariance Among Interepisode Hazards}

The unobserved inter-individual heterogeneity for the different activity purposes and the covariance among interepisode hazards is captured by the variance-covariance matrix $\Omega$ of $v_{q}$ (see Section 2.1). As indicated in Section 2.2, we do not estimate this variance-covariance matrix directly. Instead, we parameterize the likelihood function in terms of the Cholesky decomposition (say $S$ ) of $\Omega$. After obtaining the estimates of $S$, the matrix $\Omega$ needs to be computed as $\Omega=S^{\prime} S$. The relevant standard errors (and $t$-statistics) of the elements of $\Omega$ are computed by re-writing the likelihood directly in terms of $\Omega$ ( $\Omega$-parameterized likelihood function), computing the estimate of $\Omega$ from the estimate of $S$ at convergence of the $S$ parameterized likelihood function, and maximizing the $\Omega$-parameterized likelihood function. This “optimization” will immediately converge and provide the necessary standard errors for the elements of $\Omega$.

The estimated variance-covariance matrix $(\hat{\Omega})$ is shown in Table 4. For ease of discussion, and because of the symmetric nature of the matrix, only the upper triangle is presented. The estimated parameters along the diagonal are highly statistically significant (except for the estimate of "other shopping”), indicating the significant presence of unobserved individual-specific factors affecting interepisode durations. Several of the off-diagonal estimates are also statistically significant at the 0.1 level of significance, indicating significant covariance among the interepisode hazards (the hypothesis of no covariance among all activity categories is strongly rejected by a likelihood ratio test; see Section 4.4). The covariance estimates indicate that the interepisode hazard for maintenance shopping is strongly correlated with the hazards for other shopping and personal business activities. That is, if an individual has an intrinsically low hazard (low participation frequency) for maintenance shopping, s/he will also have an 
intrinsically low hazard (low participation frequency) for other shopping and personal business activities. Equivalently, an individual with an intrinsically high hazard (high participation frequency) for maintenance shopping will also have an intrinsically high hazard (high participation frequency) for other shopping and personal business activities. On the other hand, there is a negative correlation between the hazard of maintenance shopping and those of social and recreational activity purposes (these, however, are not statistically significant). The hazard for "other" (non-maintenance) shopping is positively correlated with social and personal business activities (as well as maintenance shopping, as already discussed earlier). The results also show the statistically significant positive correlation between social and recreational activity participation.

Overall, four general conclusions may be drawn from Table 4. First, there are unobserved individual-specific factors that impact the hazard (participation rate) of activity engagement. Second, there is complementarity in participation in maintenance shopping, other shopping, and personal business activities due to unobserved individual factors (perhaps, a general inclination toward shopping, grooming, etc.). Third, there is a strong substitution effect between individual participation in maintenance shopping and social-recreational activities. Finally, there is a strong complementary effect in social and recreational activity participation due to unobserved individual factors (perhaps due to an overall inclination to participate in physically active and non-physically active leisure).

\subsubsection{Unobserved Intra-Individual Heterogeneity}

Unobserved intra-individual heterogeneity is captured by the variance of the gamma distribution term, $c_{q m i}$, for each activity purpose $m$. These values are estimated as follows ( $t$-statistics are in 
parentheses): (1) maintenance shopping: 0.4490 (4.633), (2) non-maintenance shopping: 0.6825 (3.978), (3) social activities: 0.5596 (4.106), (4) recreation: 0.4248 (5.029), and (5) personal business: 0.3316 (2.244). Clearly, all these variance estimates are highly significant, suggesting the presence of statistically significant intra-individual heterogeneity for all activity purposes.

The unobserved inter-individual and intra-individual heterogeneity estimates indicate the presence of heterogeneity, but do not provide an intuitive sense of the magnitude of the different sources of unobserved heterogeneity and the effect of observed heterogeneity (i.e., the effect of covariates). The next section translates the statistical estimates into more intuitive measures.

\subsubsection{Variation Components of Interepisode Hazard}

The covariate effects and the variances of the unobserved heterogeneity terms provide important information regarding the fraction of variation in the interepisode hazard explained by covariates and by unobserved factors. To see this, consider Equation (2) and take the logarithm of both sides of the equation to yield the following equation:

$\ln \lambda_{q m i}(\tau)=\ln \lambda_{m 0}(\tau)-\beta_{m}^{\prime} x_{q m i}-v_{q m}+\ln c_{q m i}$, where $c_{q m i}=\exp \left(\varpi_{q m i}\right)$.

Since the baseline hazard $\lambda_{m 0}(\tau)$ is the same across all interepisode spells for each activity purpose $m$, the variance across spells of the (log) interepisode hazard for purpose $m$ can be partitioned as follows:

$\operatorname{Var}\left[\ln \lambda_{q m i}(\tau)\right]=\operatorname{Var}\left(\beta_{m}^{\prime} x_{q m i}\right)+\left[\operatorname{Var}\left(v_{q m}\right)+\operatorname{Var}\left(\ln c_{q m i}\right)\right]$,

where $\operatorname{Var}\left(\beta_{m}^{\prime} x_{q m i}\right)$ represents the variance due to observed heterogeneity and the second term on the right hand side of the equation (shown in parenthesis) represents the variance due to unobserved heterogeneity. The variance due to unobserved heterogeneity for purpose $m$ can be further partitioned into inter-individual and intra-individual heterogeneity. The extent of 
unobserved inter-individual heterogeneity is provided by $\operatorname{Var}\left(v_{q m}\right)$, while the extent of intraindividual unobserved heterogeneity is provided by $\operatorname{Var}\left(\ln c_{q m i}\right)$.

The percentage of variation in the interepisode duration hazard explained by each of the different variance components can be computed from the estimates of $\beta_{m}$ and the estimated variance of the error components. These percentages are presented in Table 5 . The percentage of variation captured by observed and unobserved factors is indicated first. Next, within unobserved heterogeneity, the percentage of variation captured by intra- and inter-individual heterogeneity is presented in italics. Thus, the number associated with inter-individual heterogeneity in Table 5 indicates the percentage of total unobserved heterogeneity captured by inter-individual heterogeneity. Several important observations may be drawn from this table. First, there are quite substantial differences in our ability to explain the interepisode hazard across activity purposes, as can be observed from the numbers in bold (first two rows) of Table 5. The best prediction ability is for the maintenance shopping and recreational purposes, and the poorest is for participation in social activities. Second, there are also substantial variations across purposes in the percentage of total unobserved heterogeneity captured by inter-individual variation and intraindividual variation. The variation in the hazard (or equivalently, interepisode duration) due to unobserved factors is higher across individuals than within the spells of the same individual for all activity purposes except "other” (non-maintenance) shopping. That is, in the overall, individuals have reasonably well-established rhythms or cycles for participation in all activity purposes except “other” shopping, though these rhythms vary quite substantially across individuals. The rhythms within each individual are particularly well-established for maintenance shopping and recreational pursuits (see the low percentages in the "intra-individual" unobserved heterogeneity for these two activity purposes in Table 5). On the other hand, there is 
more variation (less rhythm) in the interepisode durations within an individual for personal business and social activity participations. Third, there is substantial intra-individual variations in the length of intershopping spells for the "other shopping" category. In fact, almost all unobserved heterogeneity is due to intra-individual factors than inter-individual factors. This indicates a very strong lack of rhythm (more "spur-of-the-moment” participation) within an individual in pursuing “other” (non-maintenance) shopping. Fourth, the magnitude of both interindividual (i.e., $\left.\operatorname{Var}\left(v_{q m}\right)\right)$ and intra-individual (i.e., $\left.\operatorname{Var}\left(\ln c_{q m i}\right)\right)$ unobserved heterogeneity is sizable for all activity purposes. This reinforces the need to collect multiday data that can estimate and disentangle these two sources of unobserved heterogeneity, thus allowing the accurate and reliable effect of covariates to be estimated.

\subsection{Model Fit Statistics}

The log-likelihood at convergence for the multivariate hazard model estimated in this paper with 154 parameters is -17092.2 . The corresponding number of parameters and likelihood values for other restrictive models are as follows: (1) Univariate hazard structures for each activity purpose separately, but with inter-individual heterogeneity and intra-individual unobserved heterogeneity (144 parameters) is -17124.7, and (2) Univariate naive hazard structure assigning a single hazard profile across all individuals (93 parameters) is -17836. A likelihood ratio test of the multivariate model estimated in the paper with restricted model (1) clearly indicates the significant presence of covariations in the interepisode hazards of the different activity purposes (the likelihood ratio statistic is 65, which is greater than the chi-squared value with 10 degrees of freedom at any reasonable level of significance). Similarly, comparisons of the model estimated in the paper with the model (2) indicates the need to recognize inter-individual unobserved heterogeneity and 
the significant influence of demographic, locational, and day of week factors on interepisode durations. Overall, the multivariate mixed hazard model estimated in this paper fits the data much better than any of the restrictive forms.

\section{CONCLUSIONS}

This paper has focused on examining the interepisode durations of five activity purposes over a multi-week period using a continuous six-week travel diary collected in the German cities of Karlsruhe and Halle in 1999. The methodology proposed and applied in the paper uses a hazardbased structure that addresses several econometric issues, including (1) allowing a nonparametric baseline hazard to account for non-monotonicity in the interepisode durations dynamics and spikes in the hazard based on weekly rhythm of participation in activities, (2) recognizing the interval-level nature of interepisode durations: that is, recognizing that a day is an interval of time, with several individuals having the same interepisode duration, (3) incorporating unobserved heterogeneity due to both inter-individual as well as intra-individual differences, and (4) accommodating the presence of common individual-specific unobserved factors that influence the interepisode duration hazard (or equivalently, participation rates) of multiple activity purposes. All of these econometric issues are considered within an efficient, unifying, framework that is easy to implement. The efficiency originates from the use of a gamma distribution for intra-individual unobserved heterogeneity, so that the probability of an interepisode spell terminating at a particular length, conditional on the error terms generating inter-individual unobserved heterogeneity and covariance among interepisode hazards, takes a closed form structure. The efficiency also is a consequence of a single underlying variancecovariance matrix forming the basis to capture both inter-individual heterogeneity in interepisode 
hazards as well as covariance in the different hazards for each individual. As a result, the dimensionality of integration during estimation is the same as the number of activity purposes in the analysis. Overall, the multivariate hazard model presented here represents a very efficient, powerful, structure for the joint analysis of multiple duration categories. To our knowledge, this is the first formulation and application of a multivariate non-parametric hazard structure in the econometric literature. The resulting model is estimated using a simulated maximum likelihood method.

The application of the multivariate model to examine interepisode durations in five activity purposes using the German MobiDrive data provides several important insights. First, individuals are more likely to engage in shopping activities (both maintenance shopping and nomaintenance shopping) as the time elapsed since their previous participation increases. However, there is no such clear duration dynamics for non-shopping activities. Second, there is a very distinct weekly rhythm in individuals’ participation in social, recreation, and personal business. While there is a similar rhythm even for the shopping purposes, it is not as pronounced as for the non-shopping purposes. Thus, inventory depletion appears to drive shopping participation, while weekly rhythms appear to drive non-shopping participation. Third, individual and spouse attributes, household characteristics, residential location and trip-making variables, and day of week effects have a strong influence on interepisode duration. Among these, two particularly interesting findings are the substitution effects of access to internet at home on non-maintenance shopping activity participation and the strong positive influence of the number of dogs in the household on recreational activity participation. It is also interesting to note the lack of effect of number of motorized vehicles owned by the household and the residence location/transportation service characteristics on participation rates. This latter finding may be a reflection of relatively 
consistent and good quality of transit service across all neighborhoods in Karlsruhe and Halle and/or self-selection into residential locations based on preferences to own motorized vehicles and mobility desires. Fourth, there is significant and substantial unobserved inter-individual variation in the duration hazards for the different activity purposes (varying from 10 to $77 \%$ of total unobserved heterogeneity for activity purposes), as well as significant and substantial intraindividual variation (varying from 23 to $90 \%$ of total unobserved heterogeneity for activity purposes). Thus, there is a need to collect and analyze activity participation behavior using multiday survey data. Fifth, there is a strong substitution effect between individual participation in maintenance shopping and social-recreational activities, and there is a strong complementary effect in social and recreational activities.

There are, as always, several avenues to extend the current research. First, there is no explicit accounting of the interaction among household members on individual activity episode participation behavior; rather, the effect of such interactions is accommodated implicitly using household-level variables such as marital status and spouse's employment status. As a consequence, the current modeling approach does not distinguish between independent and joint participations in activity episodes. In reality, intra-household interactions are likely to have a significant impact on the activity-travel patterns and schedules of household members. There has been growing research on this issue in the recent past, especially since Bhat and Koppelman (1999) explicitly identified the area as a critical one for future research. These recent studies recognizing intra-household interactions explicitly have all focused on a single day of analysis and a single purpose (see Wen and Koppelman, 2000; Gliebe and Koppelman, 2002; Zhang et al., 2002; Scott and Kanaroglou, 2002; Vovsha et al., 2003; Srinivasan and Bhat, 2004). Future efforts to integrate research in intra-household interactions and multi-day, multiple purpose, 
activity episode participation is an important direction in activity-travel modeling. Second, several of the independent variables used in the analysis may be co-determined with interepisode duration. For example, the need to shop frequently may lead to a higher-level of chaining the shopping episodes with other episodes. Thus, it would be more appropriate to model travel mode choice, episode chaining, internet-use, residential location, and interepisode duration jointly. Of course, there also needs to be the realization that it is not possible to model all dimensions of residential, activity, and travel choice jointly. Extensive empirical studies to establish a reasonable simplifying structure for activity-travel modeling always remains an area for further exploration (see Axhausen et al., 2004).

\section{ACKNOWLEDGEMENTS}

The authors are grateful to Lisa Macias for her help in typesetting and formatting this document. Three anonymous reviewers provided helpful comments on an earlier version of the paper. The data used was collected by the project Mobidrive funded by the German Ministry of Research and Technology undertaken by PTV AG, Karlsruhe, IVT, ETH Zürich and ISB, RWTH Aachen. 


\section{REFERENCES}

Arentze, T. A., and H. J. P. Timmermans (2004). A learning-based transportation oriented simulation system. Transportation Research Part B, 38(7), 613-633.

Axhausen, K.W., Zimmerman, Z., Schönfelder, S., Rindsfuser, G. and T. Haupt (2002). Observing the rhythms of daily life: a six week travel diary. Transportation, 29(2), 95124.

Axhausen K.W., D.M. Scott, A. König and C. Jürgens (2004) Locations, commitments and activity spaces. In M. Schreckenberg and R. Selten (eds.) Human Behaviour and Traffic Networks, 205-230, Springer, Berlin.

Bhat, C.R. (1996). A hazard-based duration model of shopping activity with nonparametric baseline specification and nonparametric control for unobserved heterogeneity. Transportation Research Part B, 30, 189-207.

Bhat, C.R. (2000a). Incorporating observed and unobserved heterogeneity in urban work travel mode choice modeling. Transportation Science, 34(2), 228-238.

Bhat, C.R. (2000b). Duration modeling. In Handbook of Transport Modelling, D.A. Hensher and K.J. Button, eds, Elsevier Science, 91-111.

Bhat, C.R. (2001). Quasi-random maximum simulated likelihood estimation of the mixed multinomial logit model. Transportation Research Part B, 35, 677-693.

Bhat, C.R. and R. Misra (2002). Comprehensive activity-travel pattern modeling system for nonworkers with empirical focus on the organization of activity episodes, Transportation Research Record, 1777, 16-24.

Bhat, C.R. (2003). Simulation estimation of mixed discrete choice models using randomized and scrambled Halton sequences. Transportation Research Part B, 37(9), 837-855.

Bhat, C.R. and F.S. Koppelman (1999). A retrospective and prospective survey of time-use research. Transportation, 26(2), 119-139.

Bhat, C.R. and H. Zhao (2002). The spatial analysis of activity stop generation. Transportation Research Part B, 36(6), 557-575.

Bhat, C.R., Frusti, T., Zhao, H., Schönfelder, S., and K.W. Axhausen (2004). Intershopping duration: an analysis using multiweek data. Transportation Research, 38B, 39-60.

Bhat, C.R. and R. Gossen (2004). A mixed multinomial logit model analysis of weekend recreational episode type choice, Transportation Research Part B, 38, 767-787.

Chalasani, V.S. and K.W. Axhausen (2004). Mobidrive 1999. Travel Survey Metadata Series, 2, Institut für Verkehrsplanung und Transportsysteme (IVT), ETH Zürich, Zürich. 
Chintagunta, P.K. and S. Haldar (1998). Investigating purchase timing behavior in two related product categories. Journal of Marketing Research, 35, 43-53.

Frusti, T., Bhat, C.R., and K.W. Axhausen (2003). An exploratory analysis of fixed commitments in individual activity-travel patterns. Transportation Research Record 1807, 101-108.

Gliebe, J. P., and F.S. Koppelman (2002). A model of joint activity participation between household members. Transportation, 29, 49-72.

Goulias, K.G. and T.G. Kim (2001). Multi-level analysis of activity and travel patterns: accounting for person- and household- specific observed and unobserved effects simultaneously. Transportation Research Record 1752, 23-31.

Hajivassiliou, A., and P.A. Ruud (1994). Classical estimation methods for LDV models using simulation. In R.F. Engle and D.L. McFadden (eds), Handbook of Econometrics, 4, North Holland, Amsterdam, 2383-2441.

Hanson, S. and J.O. Huff (1986). Classification issues in the analysis of complex travel behavior. Transportation, 13, 271-293.

Hanson, S. and J.O. Huff (1988a). Systematic variability in repetitious travel. Transportation, 15, 111-135.

Hanson, S. and J.O. Huff (1988b). Repetition and day-to-day variability in individual travel patterns: implications for classification. In Behavioral Modelling in Geography and Planning, R. Golledge and H. Timmermans, eds, Croom Helm, New York.

Hatcher, G. and H.S. Mahmassani (1992). Daily variability of route and trip scheduling decisions for the evening commute. Transportation Research Record, 1357, 72-81.

Hirsh, M., Prashker, J.N., and M. Ben-Akiva (1986). Dynamic model of weekly activity pattern. Transportation Science, 20(1), 24-36.

Huff, J.O. and S. Hanson (1986). Repetition and variability in urban travel. Geographical Analysis, 18(2), 97-113.

Huff, J.O. and S. Hanson (1990). Measurement of habitual behavior: examining systematic variability in repetitive travel. In Developments in Dynamic and Activity-Based Approaches to Travel Analysis, P. Jones, ed., Gower Publishing Co., Aldershot, England, 229-249.

Johnson and Kotz (1970). Distributions in Statistics: Continuous Univariate Distributions. Wiley, New York, Chapter 21. 
Jones, P. and M. Clark (1988). The significance and measurement of variability in travel behaviour. Transportation, 15, 65-87.

Kiefer, N.M. (1988). Econometric duration data and hazard functions. Journal of Econometric Literature, 27, 646-679.

Kim, B. and K. Park (1997). Studying patterns of consumer's grocery shopping trip. Journal of Retailing, 73(4), 501-517.

Kitamura, R. (1988). Life style and travel demand. Transportation Research Board Special Report 220, Looking Ahead: Year 2020, pp. 149-189.

Kunert, U. (1994). Weekly mobility of life cycle groups. Transportation, 21, 271-288.

Lee, L.-F. (1992). On the efficiency of methods of simulated moments and maximum simulated likelihood estimation of discrete response models. Econometric Theory, 8, 518-552.

Lillard, L.A. (1993). Simultaneous equations for hazards: marriage duration and fertility timing. Journal of Econometrics, 56, 189-217.

Ma, J. and K.G. Goulias (1997). A dynamic analysis of person and household activity and travel patterns using data from the first two waves in the Puget Sound transportation panel. Transportation, 24(3), 309-331.

Ma, J. and K.G. Goulias (1999). Application of poisson regression model to activity frequency analysis and prediction. Transportation Research Record, 1676, pp. 86-94.

Mahmassani, H.S., Hatcher, S.G. and C.G. Caplice (1997). Daily variation of trip chaining, scheduling, and path selection behavior of work commuters. In Understanding Travel Behavior in an Era of Change, P. Stopher and M. Lee-Gosselin, eds, Pergamon, Elsevier Science Ltd., Oxford, UK, 351-379.

Muthyalagari, G.R., Parashar, A., and R.M. Pendyala (2001). Measuring day-to-day variability in travel characteristics using GPS data. Presented at the $80^{\text {th }}$ Annual Meeting of the Transportation Research Board, Washington D.C., January.

Pas, E.I. (1988). Weekly travel-activity behavior. Transportation, 15, 89-109.

Pas, E.I. and F.S. Koppelman (1987). An examination of the determinants of day-to-day variability in individuals' urban travel behavior. Transportation, 14, 3-20.

Pas, E.I. and S. Sundar (1995). Intra-personal variability in daily urban travel behavior: some additional evidence. Transportation, 22, 135-150.

Pendyala, R. M., and K. G. Goulias (2002). Time use and activity perspectives in travel behavior research. Transportation, 29(1), 1-4. 
Pendyala, R.M., Yamamoto, T., and R. Kitamura (2002). On the formulation of time-space prisms to model constraints on personal activity-travel engagement. Transportation, 29, 73-94.

Schlich, R., König, A., Aschwanden, A., Kaufmann, A., and K.W. Axhausen (2000). Mobidrive: data format guide. Arbeitsberichte Verkehrs- und Raumplanung, 35, Institut für Verkehrsplanung, Transporttechnik, Strassen- und Eisenbahnbau, ETH Zürich, Zürich.

Schlich, R. (2003). Homogenous groups of travelers. Paper presented at the 10th International Conference on Travel Behaviour Research, Lucerne, August 2003.

Schlich, R. (2004). Verhaltenshomogene Gruppen in Längsschnitterhebungen. Dissertation, ETH Zürich, Zürich.

Schönfelder, S. and K.W. Axhausen (2000). Modelling the rhythms of travel using survival analysis. Paper submitted to the $80^{\text {th }}$ Annual Meeting of the Transportation Research Board, Washington, D.C., January 2001.

Schönfelder, S. and K.W. Axhausen (2004). Structure and innovation of human activity spaces, Arbeitsberichte Verkehrs- und Raumplanung, 258, IVT, ETH Zürich, Zürich.

Scott, D.M., and P.S. Kanaroglou (2002). An activity-episode generation model that captures interactions between household heads: development and empirical analysis. Transportation Research Part B, 36(10), 875-896.

Seetharaman, P.B. and P.K. Chintagunta (2003). The proportional hazard model for purchase timing; a comparison of alternative specifications. Journal of Business and Economic Statistics, 21, 368-382.

Simma, A. and K.W. Axhausen (2001). Within household allocation of travel: the case of upper Austria. Transportation Research Record, 1752, 69-75.

Srinivasan, S. and C.R. Bhat (2004). Modeling household interactions in daily in-home and outof-home maintenance activity participation. Technical paper, Department of Civil Engineering, The University of Texas at Austin.

Train, K. (2003). Discrete Choice Methods with Simulation. Cambridge University Press, Cambridge, United Kingdom.

Vovsha, P., Peterson, E., and R. Donnelly (2003). Explicit modeling of joint travel by household members: statistical evidence and applied approach. Presented at the $82^{\text {nd }}$ Annual Meeting of the Transportation Research Board, Washington, D.C.

Wen, C. H., and F. S. Koppelman (2000). A conceptual and methodological framework for the generation of activity-travel patterns. Transportation, 27, 5-23. 
Yamamoto, T., R. Kitamura, and R. M. Pendyala (2004). Comparative analysis of time-space prism vertices for out-of-home activity engagement on working and non-working days. Environment and Planning B: Planning and Design, 31, 235-250.

Zhang, J., Timmermans, H., and A. Borgers (2002). A utility-maximizing model of household time use for independent, shared, and allocated activities incorporating group decision mechanisms. Presented at the $81^{\text {st }}$ Annual Meeting of the Transportation Research Board, Washington, D.C. 


\section{LIST OF FIGURES}

Figure 1. Sample hazard for shopping activities

Figure 2. Sample hazard for non-shopping activities

Figure 3. Baseline hazard for shopping activities

Figure 4. Baseline hazard for non-shopping activities

\section{LIST OF TABLES}

Table 1. Number and Range of Interepisode Duration Spells

Table 2. Individual-Level Variable Definitions and Sample Statistics (Number of Individuals = 192)

Table 3. Multivariate Mixed Hazard Duration Model (Covariate Effects)

Table 4. Variance-Covariance of Interepisode Hazards, Only Upper-Triangle Elements Presented (t-stats in parenthesis)

Table 5. Percentage of Interepisode Hazard Variance Explained by Observed and Unobserved Factors 


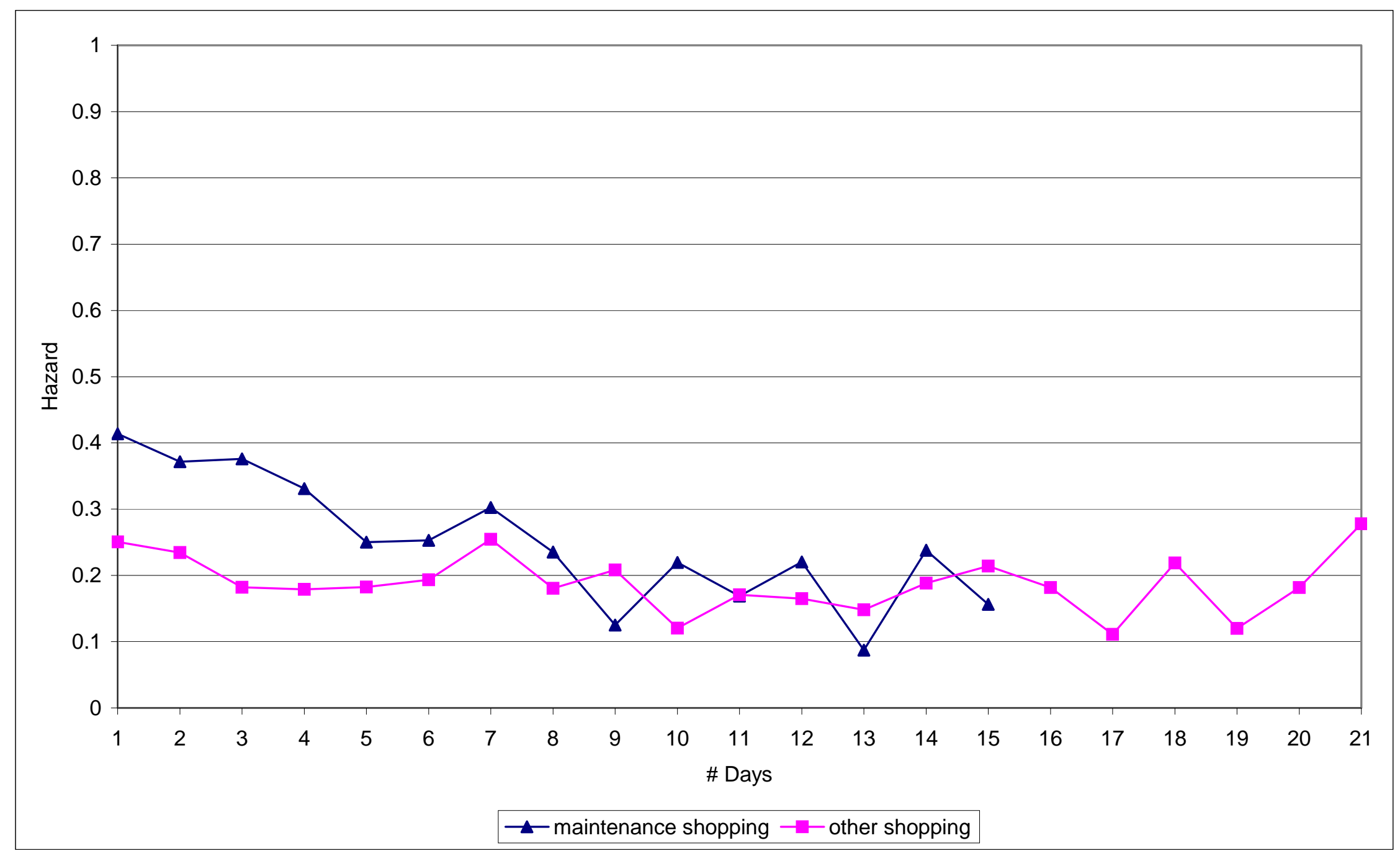

Figure 1. Sample hazard for shopping activities 


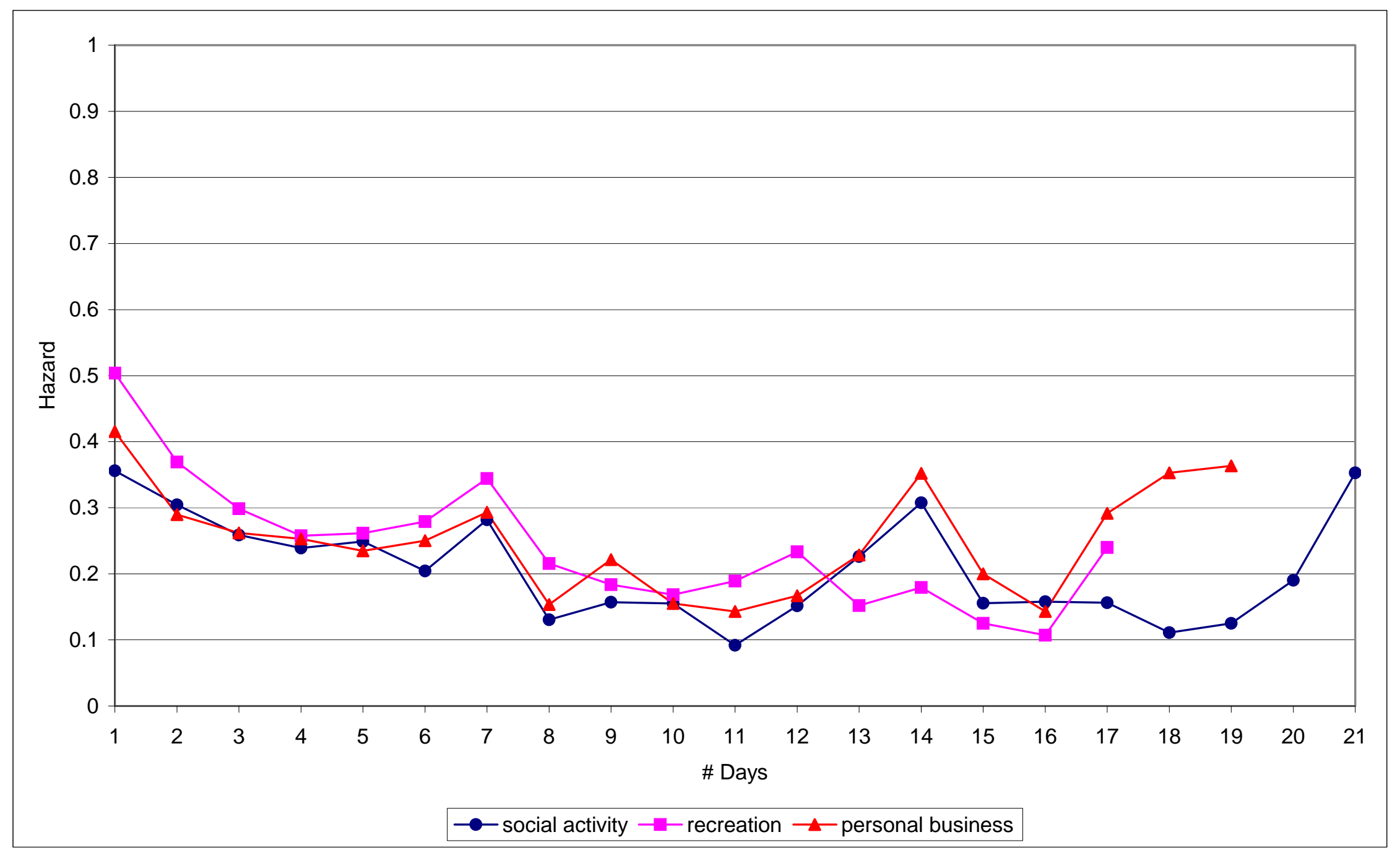

Figure 2. Sample hazard for non-shopping activities 


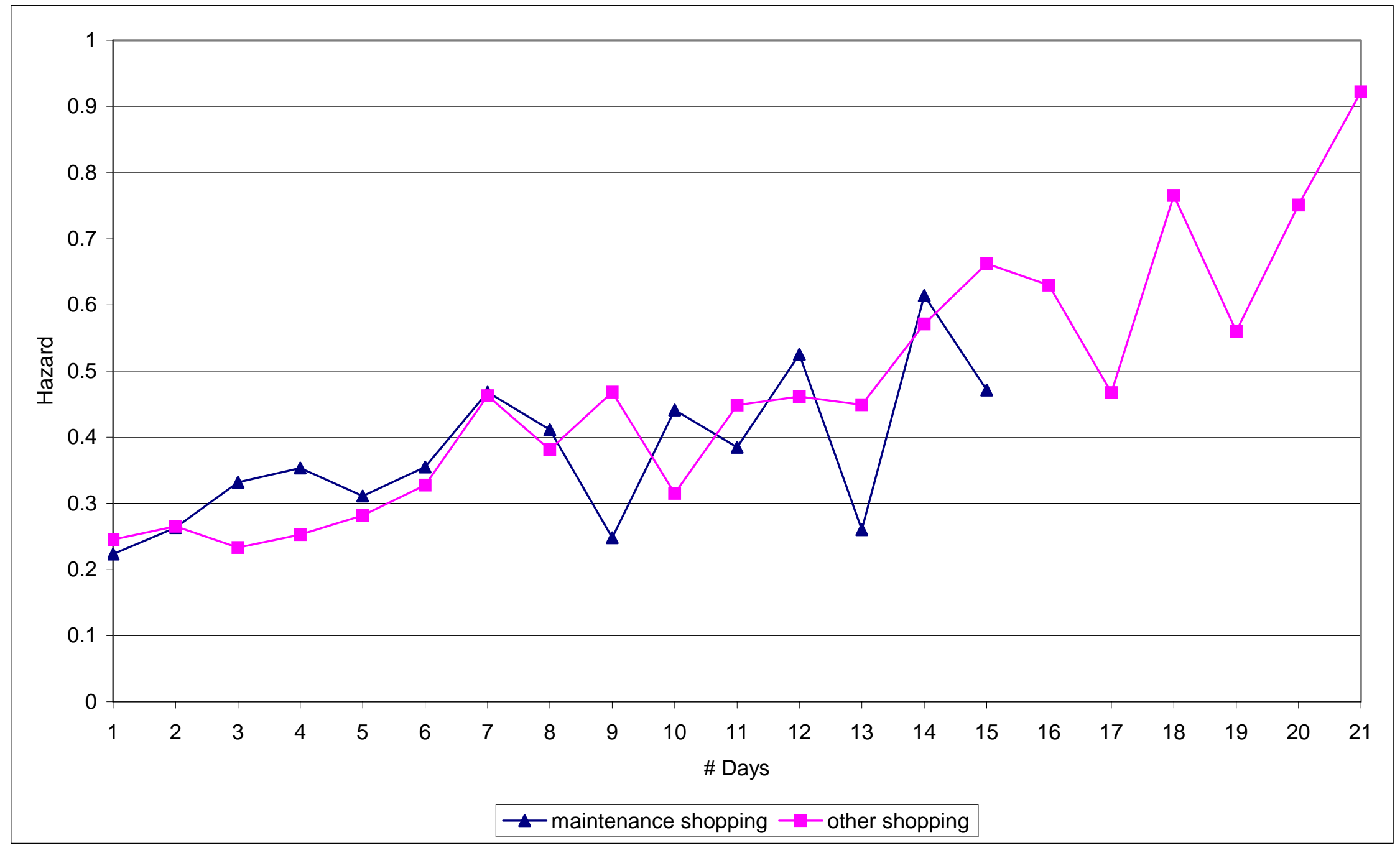

Figure 3. Baseline hazard for shopping activities 


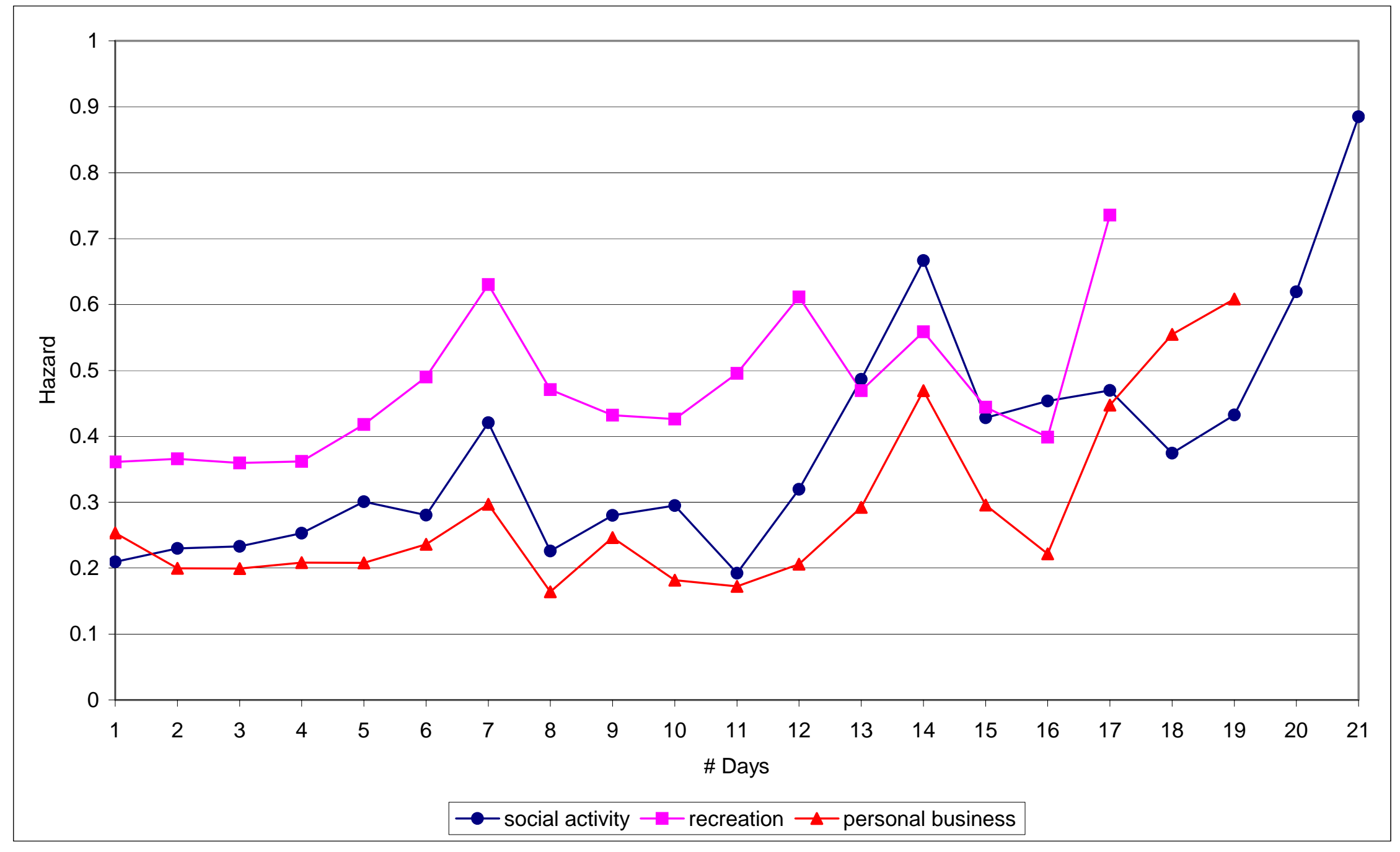

Figure 4. Baseline hazard for non-shopping activities 
Table 1. Number and Range of Interepisode Duration Spells

\begin{tabular}{|l||c|c|c||}
\hline \multicolumn{1}{|c|}{ Activity purpose } & $\begin{array}{c}\text { Number of interepisode duration } \\
\text { spells per person: } \\
\text { range (mean value) }\end{array}$ & $\begin{array}{c}\text { Interepisode duration spell length: } \\
\text { range (mean value) }\end{array}$ & $\begin{array}{c}\text { Upper end cut-off of interepisode } \\
\text { duration length for empirical } \\
\text { analysis (percentage of spells over } \\
\text { cut-off value) }\end{array}$ \\
\hline Maintenance shopping & 1 to 36 (11.78) & 1 to 31 days (2.87 days) & 16 days (1.0\%) \\
\hline Other shopping & 1 to $18(5.64)$ & 1 to 38 days (4.84 days) & 22 days (0.8\%) $(0.7 \%)$ \\
\hline Social activities & 1 to $34(8.45)$ & 1 to 37 days (3.70 days) & 18 days $(0.7 \%)$ \\
\hline Recreation & 1 to $40(12.71)$ & 1 to 38 days (2.71 days) & 20 days $(0.3 \%)$ \\
\hline Personal business & 1 to $37(9.87)$ & 1 to 26 days (3.31 days) & 22 \\
\hline
\end{tabular}


Table 2. Individual-Level Variable Definitions and Sample Statistics (Number of Individuals = 192)

\begin{tabular}{|c|c|c|c|}
\hline Variable & Definition & Mean & Std. Dev. \\
\hline $\begin{array}{l}\text { Individual and spouse characteristics } \\
\text { Full-time employed } \\
\text { Number of work hours }\left(\times 10^{-1}\right) \\
\text { Spousal employment } \\
\text { Age less than } 20 \text { years } \\
\text { Age greater than } 65 \text { years } \\
\text { Female } \\
\text { Retired } \\
\text { Married }\end{array}$ & $\begin{array}{l}1 \text { if the individual works more than } 20 \text { hours per week, } 0 \text { otherwise } \\
\text { Number of work hours per week (divided by 10) } \\
1 \text { if spouse is employed, } 0 \text { if spouse is not employed or person is not married } \\
1 \text { if the age of the individual is less than } 20 \text { years, } 0 \text { otherwise } \\
1 \text { if the age of the individual is greater than years, } 0 \text { otherwise } \\
1 \text { if the individual is a female, } 0 \text { otherwise } \\
1 \text { if the individual is retired, } 0 \text { otherwise } \\
1 \text { if the individual is married, } 0 \text { otherwise }\end{array}$ & $\begin{array}{l}0.4948 \\
2.1661 \\
0.4479 \\
0.0781 \\
0.0833 \\
0.5313 \\
0.2031 \\
0.6250\end{array}$ & $\begin{array}{l}0.5013 \\
2.0631 \\
0.4986 \\
0.2691 \\
0.2771 \\
0.5003 \\
0.4034 \\
0.4850\end{array}$ \\
\hline $\begin{array}{l}\text { Household Characteristics } \\
\text { Nuclear Family } \\
\text { Income (000s) } \\
\text { Number of motorized vehicles } \\
\text { Single family or duplex dwelling } \\
\text { Access to internet at home } \\
\text { Presence of dogs }\end{array}$ & $\begin{array}{l}1 \text { if family includes parents and one or more children, } 0 \text { otherwise } \\
\text { Monthly household income (in 1000s of Deutche Marks)* } \\
\text { Number of motorized vehicles in the household } \\
1 \text { if the household lives in a single family or duplex dwelling unit, } 0 \text { otherwise } \\
1 \text { if the individual has private access to e-mail, } 0 \text { otherwise } \\
1 \text { if dogs are present in household, } 0 \text { otherwise }\end{array}$ & $\begin{array}{l}0.3854 \\
4.3050 \\
1.2100 \\
0.2135 \\
0.2292 \\
0.0938\end{array}$ & $\begin{array}{l}0.4880 \\
2.0703 \\
0.7170 \\
0.4109 \\
0.4214 \\
0.2920\end{array}$ \\
\hline $\begin{array}{l}\text { Location and trip-making characteristics } \\
\text { Karlsruhe } \\
\text { Car is the primary mode for: } \\
\text { Maintenance shopping } \\
\text { Other shopping } \\
\text { Social activities } \\
\text { Recreation } \\
\text { Personal business } \\
\text { Percentage of episodes chained for: } \\
\text { Maintenance shopping } \\
\text { Other shopping } \\
\text { Social activities } \\
\text { Recreation } \\
\text { Personal business } \\
\text { Suburban residence } \\
\text { Excellent transit service }\end{array}$ & $\begin{array}{l}1 \text { if the household is in Karlsruhe, } 0 \text { otherwise } \\
1 \text { if car is the most frequently used mode for maintenance shopping, } 0 \text { otherwise } \\
1 \text { if car is the most frequently used mode for other shopping, } 0 \text { otherwise } \\
1 \text { if car is the most frequently used mode for social activities, } 0 \text { otherwise } \\
1 \text { if car is the most frequently used mode for recreation, } 0 \text { otherwise } \\
1 \text { if car is the most frequently used mode for personal business, } 0 \text { otherwise } \\
\text { Percentage of maintenance shopping episodes chained with other activities } \\
\text { Percentage of other shopping episodes chained with other activities } \\
\text { Percentage of social activity episodes chained with other activities } \\
\text { Percentage of recreation activity episodes chained with other activities } \\
\text { Percentage of personal business activity episodes chained with other activities } \\
1 \text { if the household is in suburban area, } 0 \text { otherwise } \\
1 \text { if access to bus, light rail and heavy rail are all within } 25 \text { meters of home, } 0 \text { otherwise }\end{array}$ & $\begin{array}{l}0.6250 \\
0.4427 \\
0.6042 \\
0.6458 \\
0.5312 \\
0.5313 \\
0.4646 \\
0.5422 \\
0.3780 \\
0.4689 \\
0.5410 \\
0.1979 \\
0.1667\end{array}$ & $\begin{array}{l}0.7057 \\
0.4980 \\
0.4903 \\
0.4795 \\
0.5003 \\
0.5003 \\
\\
0.3099 \\
0.3300 \\
0.2852 \\
0.2721 \\
0.2858 \\
0.3995 \\
0.3737\end{array}$ \\
\hline
\end{tabular}

* 1 DM = 0.548 USD = 0.5113 EUR (based on Oct 1, 1999 conversion rates; http://www.xe.com/ict/) 
Table 3. Multivariate Mixed Hazard Duration Model (Covariate Effects)

\begin{tabular}{|c|c|c|c|c|c|c|c|c|c|c|}
\hline \multirow[t]{2}{*}{ Covariates } & \multicolumn{2}{|c|}{$\begin{array}{l}\text { Maintenance } \\
\text { shopping }\end{array}$} & \multicolumn{2}{|c|}{$\begin{array}{c}\text { Other (non- } \\
\text { maintenance) } \\
\text { shopping }\end{array}$} & \multicolumn{2}{|c|}{ Social activities } & \multicolumn{2}{|c|}{ Recreation } & \multicolumn{2}{|c|}{ Personal business } \\
\hline & Param. & t-stat. & Param. & t-stat. & Param. & t-stat. & Param. & t-stat. & Param. & t-stat. \\
\hline \multicolumn{11}{|l|}{$\begin{array}{l}\text { Individual and spouse characteristics } \\
\text { Employment related }\end{array}$} \\
\hline Full-time employed & - & - & 0.2507 & 2.51 & - & - & -0.3357 & -1.18 & - & - \\
\hline Number of work hours $\left(\times 10^{-1}\right)$ & 0.0784 & 2.51 & - & - & - & - & 0.1684 & 2.29 & - & - \\
\hline Spousal employment & -0.1908 & -1.55 & - & - & - & - & - & - & - & - \\
\hline Age related & - & - & - & - & - & - & - & - & - & - \\
\hline Age less than 20 years & 0.8806 & 3.79 & - & - & -0.6318 & 3.02 & 0.4049 & 1.99 & 0.3028 & 1.82 \\
\hline Age greater than 65 years & - & - & - & - & - & - & - & - & -0.2013 & -1.22 \\
\hline Other variables & & & & & & & & & & \\
\hline Female & -0.5305 & -4.51 & - & - & - & - & 0.2670 & 2.32 & - & - \\
\hline Retired & -0.2895 & -1.86 & - & - & - & - & - & - & -0.2239 & -1.75 \\
\hline Married & - & - & - & - & - & - & 0.1532 & 1.16 & - & - \\
\hline Household Characteristics & & & & & & & & & & \\
\hline Nuclear Family & -2.0960 & -1.65 & - & - & - & - & 0.3237 & 2.08 & - & - \\
\hline Income (000s of DM) & - & - & -0.0362 & -1.31 & 0.0686 & 2.41 & -0.1150 & -3.28 & - & - \\
\hline Number of motorized vehicles & - & - & 0.0954 & 1.28 & - & - & - & - & - & - \\
\hline Single family or duplex dwelling & 0.2287 & 1.72 & - & - & - & - & 0.5882 & 3.97 & - & - \\
\hline Access to internet at home & - & - & 0.3738 & 2.78 & - & - & - & - & - & - \\
\hline Presence of dogs & - & - & - & - & - & - & -1.2872 & -5.98 & - & - \\
\hline Location and trip-making characteristics & & & & & & & & & & \\
\hline Karlsruhe & - & - & - & - & -0.4227 & -3.32 & - & - & -0.2310 & -2.52 \\
\hline Car is the primary mode for activity & 0.4547 & 3.89 & 0.0922 & 0.95 & - & - & - & - & & \\
\hline Percentage of episodes chained & -0.2905 & -1.84 & -0.2837 & -1.62 & -0.3468 & -1.59 & - & - & -0.1395 & -0.86 \\
\hline Suburban residence & - & - & - & - & - & - & - & - & -0.1569 & -1.62 \\
\hline Excellent transit service & - & - & - & - & - & - & - & - & -0.2855 & -2.54 \\
\hline Day of the week variables & & & & & & & & & & \\
\hline Friday & -0.3308 & -4.56 & - & - & - & - & - & - & - & - \\
\hline Saturday & -0.2302 & -3.00 & - & - & - & - & - & - & - & - \\
\hline Sunday & -0.3999 & -1.75 & -0.3234 & -1.35 & - & - & - & - & - & - \\
\hline Monday & - & - & - & - & -0.2332 & -1.78 & - & - & - & - \\
\hline Employed*weekend & - & - & - & - & - & - & -0.1971 & -2.24 & - & - \\
\hline
\end{tabular}


Table 4. Variance-Covariance of Interepisode Hazards, Only Upper-Triangle Elements Presented (t-stats in parenthesis)

\begin{tabular}{|c|c|c|c|c|c|}
\hline Activity purpose & $\begin{array}{c}\text { Maintenance } \\
\text { shopping }\end{array}$ & Other shopping & Social activities & Recreation & Personal business \\
\hline \multirow{2}{*}{ Maintenance shopping } & 0.5621 & 0.1211 & -0.0216 & -0.0575 & 0.1632 \\
\hline & $(5.36)$ & $(2.61)$ & $(-0.51)$ & $(-1.40)$ & $(4.06)$ \\
\hline \multirow{2}{*}{ Other shopping } & \multirow[t]{2}{*}{-} & 0.064 & 0.0433 & 0.0032 & 0.1033 \\
\hline & & $(1.54)$ & $(1.65)$ & $(0.23)$ & $(2.82)$ \\
\hline \multirow{2}{*}{ Social activities } & \multirow[t]{2}{*}{-} & \multirow[t]{2}{*}{-} & 0.4421 & 0.0738 & 0.0561 \\
\hline & & & $(4.13)$ & $(2.13)$ & $(1.66)$ \\
\hline \multirow{2}{*}{ Recreation } & \multirow[t]{2}{*}{-} & \multirow[t]{2}{*}{-} & \multirow[t]{2}{*}{-} & 0.661 & -0.0319 \\
\hline & & & & (5.68) & $(-.90)$ \\
\hline \multirow{2}{*}{ Personal business } & \multirow[t]{2}{*}{-} & \multirow[t]{2}{*}{-} & \multirow[t]{2}{*}{-} & \multirow[t]{2}{*}{-} & 0.2105 \\
\hline & & & & & $(4.24)$ \\
\hline
\end{tabular}


Table 5. Percentage of Interepisode Hazard Variance Explained by Observed and Unobserved Factors

\begin{tabular}{||c|c|c|c|c|c|}
\hline Heterogeneity source & $\begin{array}{c}\text { Maintenance } \\
\text { shopping }\end{array}$ & $\begin{array}{c}\text { Other } \\
\text { shopping }\end{array}$ & Social activities & Recreation & $\begin{array}{c}\text { Personal } \\
\text { business }\end{array}$ \\
\hline \hline Observed heterogeneity $-\operatorname{Var}\left(\beta_{m}^{\prime} x_{q m i}\right)$ & $\mathbf{2 4}$ & $\mathbf{1 6}$ & $\mathbf{9}$ & $\mathbf{2 2}$ & $\mathbf{1 4}$ \\
Unobserved heterogeneity & $\mathbf{7 6}$ & $\mathbf{8 4}$ & $\mathbf{9 1}$ & $\mathbf{7 8}$ & 77 \\
Inter-individual* $-\operatorname{Var}\left(v_{q m}\right)$ & 72 & 10 & 54 & 65 \\
Intra-individual* $-\operatorname{Var}\left(\ln c_{q m i}\right)$ & 28 & 90 & 46 & 23 & 35 \\
\hline
\end{tabular}

* The numbers in each column for these two rows indicate the percentage of total unobserved heterogeneity captured by inter-individual and intraindividual unobserved heterogeneity. Thus, the numbers corresponding to maintenance shopping indicate that $72 \%$ of the total variation in unobserved factors affecting the interepisode hazard for maintenance shopping is due to "between-individual" unobserved factors and 28\% is due to "withinindividual" unobserved factors. 